\title{
Percepção de idosos sobre grupo de convivência: estudo na cidade de Cajazeiras-PB
}

\author{
Elderly's perceptions of living groups: study in the city of Cajazeiras-PB
}

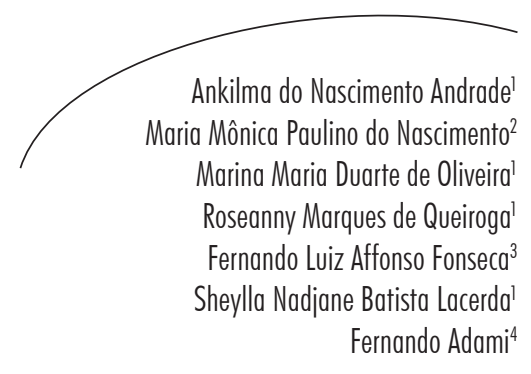

Resumo

Objetivo: investigar percepções de idosos sobre grupos de convivência. Método: estudo exploratório, com abordagem qualitativa, realizado em seis grupos de convivência da cidade de Cajazeiras-PB, Brasil, no período de setembro a outubro de 2010, utilizando a técnica de discurso do sujeito coletivo. Resultados: dos 60 participantes deste estudo, 48 (80\%) eram mulheres, 21 (35\%) tinham entre 65 e 69 anos, 30 (50\%) eram viúvos, 46 (77\%) aposentados, $32(53 \%)$ não concluíram o ensino fundamental, 40 (67\%) moravam acompanhados de familiares, 25 (42\%) tinham entre seis e dez anos de participação nos grupos, $33(55 \%)$ participavam espontaneamente e 30 (50\%) apontaram a dança como a melhor atividade desenvolvida no grupo. Diante dos questionamentos, foram obtidas as ideias centrais e os discursos coletivos representados por três temas: razões/motivos para idosos buscarem grupos de convivência; importância dos encontros com o grupo para os idosos; mudanças ocorridas na vida após o ingresso no grupo. Dos temas, foram extraídas as ideias centrais: solidão, lazer, convivência, liberdade, mudou tudo, vontade de viver. Conclusão: Os grupos proporcionam ganhos para os idosos, sinalizando entre estes o direito de envelhecer com dignidade e melhorando a qualidade de vida.

\section{Abstract}

Objective: To investigate the perception of elderly people on living groups. Method: An exploratory study with qualitative approach, performed in six living groups in the city of Cajazeiras-PB, Brazil, in September and October 2010, using the discourse of the collective subject. Results: Of the 60 study participants, 48 (80\%) were women, 21 (35\%) were between 65-69 years, 30 (50\%) were widowed, $46(77 \%)$ were retired, 32 $(53 \%)$ have not completed primary education, 40 (67\%) lived with relatives, $25(42 \%)$ between six and ten years of participation groups, 33 (55\%) and $30(50 \%)$ participated

Palavras-chave: Saúde do idoso. Centros de convivência e lazer. Compreensão.
Key words: Health of the Elderly. Centers of Connivance and Leisure. Comprehension.

\footnotetext{
Departamento de Enfermagem. Faculdade Santa Maria. Cajazeiras, PB, Brasil.

2 Unidade Acadêmica de Enfermagem. Universidade Federal de Campina Grande. Campina Grande, PB, Brasil.

3 Departamento de Ciências Biológicas, Instituto de Ciências Químicas, Ambientais e Farmacêuticas Universidade Federal de São Paulo. Diadema, SP, Brasil.

4 Departamento de Saúde da Coletividade. Faculdade de Medicina do ABC. Santo André, SP, Brasil.
} 
spontaneously pointed to the dance as the best activity developed in the group. Through the collected data we obtained the main ideas and the collective discourses represented by three themes: reasons/motives for elderly seek living groups; importance of meetings with the group for the elderly; life changes after joining the group. From the themes we extracted the main ideas: solitude, leisure, coexistence, freedom, everything changed, will to live. Conclusion: Groups provide benefits for the elderly, emphasizing among these the right to age with dignity and improving the quality of life.

\section{INTRODUÇÃO}

Como processo natural do envelhecimento, o indivíduo passa por modificações fisiológicas, com maior fragilidade e vulnerabilidade a intercorrências patológicas, nos aspectos biológico, psicológico (afetivo, emocional e cognitivo) e social. ${ }^{1}$

Osidososbrasileirosconvivem constantemente com a desvalorização das aposentadorias e pensões, medo, depressão, carência de assistência e atividades de lazer, abandono em hospitais ou instituições de longa permanência e dificuldades para assegurar alguma assistência por meio de planos de saúde. À desinformação, o preconceito e o desrespeito aos mesmos unem-se ao pouco investimentos públicos para atendimento às necessidades específicas desta população. ${ }^{2}$

Os grupos de convivência surgem como contribuição para envelhecimento saudável e com qualidade. ${ }^{3} \mathrm{E}$ a participação dos idosos nos mesmos pode trazer diversos benefícios, como: afastar a solidão, propiciar amizades, aumentar a autoestima, melhorar a integração com familiares, resgatar valores pessoais e sociais, oferecer suporte social e a adoção de um estilo devida mais ativo, pois nestes são realizadas atividades de lazer, culturais, intelectuais, físicas, manuais, artísticas e de convívio grupal. ${ }^{4}$ Dessa forma, alguns questionamentos surgem na perspectiva da compreensão do sucesso na articulação do grupo, como: qual o significado dos grupos para quem participa? Existem incentivos para adesão do idoso aos grupos de convivência? Qual o impacto causado na vida do idoso a partir da inserção em grupos?
A motivação para abordar esse tema ocorreu por afinidade com a área da Geriatria e Gerontologia, bem como por ser uma temática na qual as discussões e investigações ainda são pouco exploradas. Desta forma, torna-se relevante realizar estudos que abranjam os benefícios e mudanças ocorridas na vida dos idosos a partir da inserção em grupos de convivência.

Os resultados do estudo poderão servir de incentivo a outras pesquisas, tendo como foco grupos de convivência para idosos, visando, assim, ampliação dessas atividades. A pesquisa poderá contribuir para que a sociedade e as autoridades revejam a situação dos idosos, dando-lhes o direito de envelhecer ativamente e com dignidade. Espera-se, também, que a partir da divulgação dos resultados, haja maior sensibilização dos profissionais de saúde, para que estes valorizem ainda mais o bem-estar de pessoas idosas, promovendo, assim, melhor qualidade de vida para essas pessoas.

Por fim, ao considerar a necessidade de conhecer os motivos que levaram os idosos a procurarem atividades em grupos, como também a escassez de discussão sobre este tema na realidade local, este estudo objetivou investigar a percepção de idosos acerca dos grupos de convivência.

\section{MÉTODO}

Estudo do tipo exploratório-descritivo, com abordagem qualitativa, desenvolvido em seis grupos de convivência para idosos na cidade de CajazeirasPB. Esse cenário foi escolhido por apresentar facilidade de acesso para os pesquisadores. 
A população foi composta de 593 idosos cadastrados, sendoquealgunsidososparticipavam de mais de um grupo. Após a realização das visitas nesses centros para explicação e convite para participar da pesquisa, 87 idosos mostraram interesse, mas após a aplicação dos critérios de inclusão, restaram 60.

Os critérios de inclusão foram: ter idade igual ou superior a 60 anos, participar dos encontros com o grupo no mínimo há seis meses, ter assiduidade aos encontros, ser capaz de entender o objetivo da proposta do estudo e aceitar participar da pesquisa, assinando o Termo de Consentimento Livre e Esclarecido (TCLE). Foram excluídos os idosos incapazes de compreender as perguntas e os que não estavam presentes no momento da coleta de dados.

Para o processamento da coleta de dados, foi utilizado questionário elaborado pelos autores, direcionado aos idosos que participavam dos grupos de convivência. Os dados foram coletados entre setembro e outubro de 2010, nos locais onde funcionavam os referidos grupos de convivência, com datas e horários previamente agendados pela coordenação de cada grupo. A técnica para a realização da coleta foi a entrevista, que foi gravada e, em seguida, transcrita para análise.

Optou-se pela técnica de discurso do sujeito coletivo (DSC), que parte do pressuposto de que o pensamento coletivo pode ser visto como conjunto de discursos sobre um dado tema. Essa técnica visa dar luz ao conjunto de individualidades semânticas componentes do imaginário social e consiste na extração, de cada depoimento, das expressões-chave que são as peculiaridades do pensamento que se parecem, e as ideias centrais que são as expressões que fazem relato de maneira sucinta do depoimento analisado, sendo construído um discurso único: o DSC, relatado na primeira pessoa do singular, tem como objetivo manifestar o pensamento da coletividade, de forma lógica e coerente, com as expressões da população que irá se expor sobre determinado tema. ${ }^{5}$

Mediante os dados coletados, foram obtidas as ideias centrais e os discursos coletivos representados por três temas: razões/motivos para idosos buscarem grupos de convivência; importância dos encontros com o grupo para os idosos; mudanças ocorridas na vida após o ingresso no grupo. Dos temas, foram extraídas as ideias centrais: solidão, lazer, convivência, liberdade, mudou tudo, vontade de viver.

Este estudo foi aprovado pelo Comitê de Ética em Pesquisa da Faculdade Santa Maria, conforme protocolo n ${ }^{\circ} 566082010$, respeitando os critérios estabelecidos pela Resolução n¹96/96, do Conselho Nacional de Saúde, assegurando os direitos e deveres no que diz respeito à comunidade científica e aos sujeitos da pesquisa. ${ }^{8}$ Para garantir o anonimato dos entrevistados, seus nomes foram substituídos durante a apresentação e análise dos resultados pela letra "S" que corresponde à expressão "sujeitos da pesquisa".

\section{RESULTADOS}

Referente ao gênero da amostra em estudo, observou-se que $48(80 \%)$ entrevistados eram do sexo feminino, $21(35 \%)$ possuíam entre 65 e 69 anos e $30(50 \%)$ eram viúvos. No tocante à aposentadoria, $46(77 \%)$ recebiam este benefício, $32(53 \%)$ não concluíram o ensino fundamental, 40 (67\%) dos idosos moravam acompanhados de familiares, como filhos, netos, genros, noras e com amiga (tabela 1). 
Tabela 1. Caracterização dos sujeitos. Cajazeiras-PB, 2010

\begin{tabular}{ccc}
\hline Gênero & $\mathrm{n}$ & $\%$ \\
\hline Feminino & 48 & 80 \\
Masculino & 12 & 20 \\
Faixa etária & & \\
$60-64$ & 13 & 22 \\
$65-69$ & 21 & 35 \\
$70-74$ & 16 & 27 \\
$75-79$ & 07 & 11 \\
$80-84$ & 03 & 5
\end{tabular}

Estado civil

Viúvo(a)

$30-50$

Casado(a)

$20 \quad 34$

Separado(a)

$5-8$

Amasiado(a)

$3-5$

Solteiro(a)

$2-3$

Aposentadoria

$\mathrm{N} \quad \%$

$\operatorname{Sim}$

$46 \quad 77$

Não

Escolaridade

Não alfabetizado

$20 \quad 33$

$1^{\circ}$ grau incompleto

$32 \quad 53$

$1^{\circ}$ grau completo

325

$2^{\circ}$ grau incompleto

$4 \quad 7$

$2^{\circ}$ grau completo

12

Arranjo domiciliar

$\begin{array}{lll}\text { Mora Acompanhado(a) } & 40 & 67\end{array}$

\begin{tabular}{lcc} 
Mora sozinho(a) & 20 & 33 \\
\hline Total & 60 & 100
\end{tabular}

Ao verificar o tempo de participação dos encontros nos grupos de convivência, 25 (42\%) tinham entre seis e dez anos. Em relação ao incentivo para participar nos encontros, $33(55 \%)$ responderam que não havia incentivo da família, que participavam espontaneamente. Quando indagados sobre as atividades que gostavam de realizar em grupo, $30(50 \%)$ apontaram a dança (tabela 2). 
Tabela 2. Distribuição dos idosos segundo tempo de participação em grupos de convivência, apoio para participar dos encontros e atividade que mais gosta no grupo. Cajazeiras-PB, 2010

\begin{tabular}{lcc}
\hline Tempo de participação em grupos & $\mathrm{n}$ & $\%$ \\
\hline $1-5$ anos & 23 & 38 \\
6-10 anos & 25 & 42 \\
$11-15$ anos & 7 & 12 \\
$16-20$ anos & 3 & 5 \\
$21-25$ anos & 2 & 3 \\
Apoio para ir aos encontros & & \\
Não & 33 & 55 \\
Sim & 27 & 45 \\
Atividade que mais gosta & & \\
Dança & 30 & 50 \\
Educação física & 16 & 27 \\
Passeio & 12 & 20 \\
Artesanato & 2 & 3 \\
\hline Total & 60 & 100 \\
\hline
\end{tabular}

Reportando-se ao questionamento sobre as razões/motivos para idosos buscarem grupos de convivência, emergiram duas ideias centrais: solidão e lazer, conforme discursos abaixo.

IC 1/DSC 1 - Solidão

Eu vivia muito só, em casa sem fazer nada, quando soube dos encontros vim e gostei e não vou deixar de vir mais. Quando fiquei viuva, fiquei me sentindo muito sozinha, não tinha nenbuma atividade, fui convidada, vim e não perdi mais um encontro (S1, S17, S28).

\section{IC 2/DSC 2 - Lazer}

Eu vim para o grupo atrás de diversão, laz̧er e distração, porque vivia só, sem atividade, sem ter o que fazer, ai aqui a gente se distrai e faz, amizades. Fui convidada por vizinhas para vir, disseram que era tudo alegria e diversão aqui, e vim e gostei e não falto mais nenbum (S11, S39, S46).
Questionados sobre a importância dos encontros com o grupo para os idosos, os discursos que seguem mostram as ideias centrais de convivência e liberdade.

IC 1/DSC 1 - Convivência

Aqui a gente se sente melhor, convive com pessoas da nossa idade, cria um circulo de amizades. Me sinto bem feliv, quando venho aqui encontro os amigos, passeia e não cai na velbice (S7, S33, S55).

IC 2/DSC 2 - Liberdade

Me sinto outra pessoa quando estou aqui, desabafa, conversa e acaba a solidão. É um divertimento os encontros, fico alegre e de bem com a vida com boa saúde. É uma distração, aqui a gente se sente a vontade e tem mais liberdade de expressão (S5, S40, S53). 
Indagados sobre as mudanças ocorridas na vida após o ingresso em grupos de convivência, emergem dos discursos as ideias centrais de mudança em tudo e a vontade de viver.

IC 1/DSC 1 - Mudou tudo

Fiquei mais ativa, mais alegre, me sinto mais jovem, tudo se renovou, mudou para melhor. A saúde melhorou, sinto o corpo mais à vontade depois dos exercicios e da dança, tenho mais disposição. Estava em depressão antes de participar dos encontros, e hoje tudo mudou na minha vida, sou mais feliz, mais saudável e cheia de amigos (S6, S43, S50).

\section{IC 2/DSC 2 - Vontade de viver}

Hoje sou outra pessoa, alto astral, feliz e de bem com a vida, aqui nada de tristera, a vida é bela. Mais saudável e feliz, me sinto bem, é uma vontade de viver. Descobri a vida depois daqui, pois conbeci novos lugares, que nem imaginava conbecer, como a praia, é muito bom, aqui a vida tem sentido (S6, S33, S28).

\section{DISCUSSÃO}

Percebeu-se nos encontros a predominância de mulheres em relação aos homens, o que pode estar relacionado à maior expectativa de vida por parte da população feminina ${ }^{6,7}$. Identificouse também a resistência masculina, que por sua vez foi um fator significativo, pois quando perguntadas pelos esposos, as casadas respondiam que os companheiros, por preconceito, não as acompanhavam aos encontros.

Achados semelhantes foram encontrados em outro estudo, nos quais a participação masculina não ultrapassou $10 \%$, o que se justificou pelo processo de feminização da velhice. ${ }^{8}$ A motivação feminina em participar das atividades de lazer é diferente da masculina, pois as mulheres, mais do que os homens, buscam entrar em contato com novas pessoas e ampliar o círculo de amizades. Pode-se supor também que as mulheres têm maior atenção com a saúde e com o autocuidado; da mesma forma, as idosas que frequentam grupos de terceira idade em sua maioria não desenvolveram atividades profissionais - ao contrário, foram donas-de-casa, mães e esposas.
A baixa participação de idosos entre 75 e 84 anos pode estar relacionada ao grau de dependências e comorbidades, devido ao aumento da idade, pois esses fatores podem limitar o acesso e a participação dos idosos em encontros com grupo. $\mathrm{O}$ envelhecimento populacional brasileiro caracteriza-se pelo acúmulo de incapacidades progressivas nas atividades funcionais e de vida diárias, cuja mortalidade é substituída por comorbidades. A manutenção da capacidade funcional surge, portanto, como novo paradigma de saúde, relevante para o idoso. ${ }^{10}$

O grande número de viúvos frequentando os grupos pode estar relacionado ao isolamento e à solidão, por isso os grupos de convivência para a terceira idade não são apenas passatempo, como alguns acreditam; ao contrário, têm importância para os idosos, possibilitando-lhes ressocialização.

A maioria dos idosos entrevistados era aposentada e relatou que o salário se destinava a contribuir com a família e comprar medicamentos. Os idosos têm, geralmente, aposentadorias e pensões como única fonte de renda, na qual se encontram bastante defasada, o que lhes confere baixo poder aquisitivo. ${ }^{11,12}$

A queda das taxas de fecundidade e mortalidade vem ocasionando mudança na estrutura etária, com diminuição relativa da população mais jovem e o aumento proporcional dos idosos..$^{10}$ Os números revelam a importância cada vez maior das políticas públicas relativas à previdência, diante do crescente número de indivíduos aposentados, em relação àqueles em atividade.

Percebeu-se baixa escolaridade entre os idosos pesquisados, apesar de a maioria ter relatado que frequentou a escola para aprender a assinar o nome, pois não havia tempo para estudar, principalmente porque tinham que trabalhar. E o fato de muitos relatarem morar sozinhos é preocupante, pois a solidão é porta de entrada para várias patologias, inclusive depressão. Pessoas que moram sozinhas não têm com quem dividir anseios, dúvidas, medos e alegrias. 
Em estudo realizado, verificou-se que a maioria dos idosos frequentava grupos de convivência há mais de cinco anos, o que sugere que estes estavam encontrando o que buscavam e confirma a possibilidade de utilização de grupos de convivência como veículos para intensificar a qualidade de vida. ${ }^{12,13} \mathrm{O}$ apoio, o incentivo e o reconhecimento dos familiares são percebidos pelos idosos como reforço para que continuem a participar dos grupos, considerando que os indivíduos têm necessidade de suporte familiar e social, que se intensificam na velhice. ${ }^{14}$

A participação dos idosos em grupos de terceira idade, especialmente naqueles que têm como finalidade primordial a dança (bailes), favorece a maior ocorrência de encontros afetivos, ampliando a possibilidade de o idoso continuar exercendo suas atividades. Além disso, o aumento do número da população de anciãos, aliado à probabilidade de envelhecer com saúde, aponta que existe considerável contingente de pessoas frequentando grupos e, por conseguinte, tendentes a preservar a capacidade funcional. ${ }^{15}$

É preciso aceitar que envelhecer faz parte do ciclo da vida e deve-se estar preparado física e psicologicamente para que a velhice seja bemsucedida. No entanto, grupos de convivência surgem como proposta de trabalho humanizado para que idosos reconstruam relações por meio do vínculo com outros indivíduos da mesma idade e que, ao frequentarem os grupos, adquiram novos conhecimentos e encontrem variedade de práticas sociais.

A velhice é uma fase da vida em que as patologias vão ocorrendo gradativamente. Com vistas a prolongar o tempo de vida com saúde, é necessário que o idoso realize continuamente atividades físicas e participe da vida social. ${ }^{16}$ Como se observou, os principais motivos citados pelos idosos para procurar os grupos foram a solidão e a necessidade de atividades de lazer. Ao analisar os discursos, destacam-se as perdas afetivas, pois muitas das idosas entrevistadas haviam perdido seus esposos e viviam muito sozinhas, sem atividades, e quando foram convidadas por amigas/vizinhas a participar de grupos, aceitaram o convite.
A solidão é um conceito que pode ser interpretado de várias maneiras: é apontada frequentemente como medida objetiva ou antítese de apoio social, podendo ser descrita como deprivação percebida de contato social, falta de pessoas disponíveis ou desejosas de partilhar experiências sociais e emocionais. ${ }^{17} \mathrm{Já}$ o lazer foi citado pelos idosos como uma maneira de buscar diversão, brincadeira, distração, intuito de novas amizades, melhor qualidade de vida, favorecer a interação social, melhorar os sintomas depressivos, ansiedade, melhor tolerância ao estresse e aumento da autoestima, reduzindo o isolamento e favorecendo a socialização de novos grupos. ${ }^{18}$

A importância do lazer, para o idoso, existe em virtude do aumento do tempo livre, pois é por meio deste que os idosos encontram motivação e satisfação em viver mais e com qualidade. Idosos mantêm as mesmas necessidades psicológicas e sociais que possuíam nas outras fases da vida e, por isso, reconhecem e valorizam o lazer. ${ }^{18}$ Ter grupo de referência, em que se possam compartilhar alegrias, tristezas, conhecimentos, entre outros, propicia aos idosos suporte emocional e motivação para que tenham objetivos na vida. ${ }^{16}$

Conforme mostram os discursos, esses encontros são extremamente importantes para os idosos, implicando grandes significados para suas vidas, pois estes referiram a convivência e a liberdade como fatores importantes. Foi relatada pelos idosos a importância da criação do vínculo de amizades no grupo, pois viajavam e conheciam lugares novos, eram felizes e de bem com a vida, conviviam com pessoas da mesma idade e se sentiam mais à vontade. Os idosos que participavam das atividades propostas pelo grupo venciam as próprias limitações; havia aumento da autoestima, da alegria, da vontade de participar, estimulando assim outros idosos a se integrarem.

O grupo funciona como alternativa para minimizar os efeitos do envelhecimento, gerando a melhoria da qualidade de vida. Significam a possibilidade de conhecer novas pessoas, construir amizades, viajar acompanhando o 
grupo, fazer exercícios físicos, divertir-se, entre outras razões, mudanças que acontecem na vida de idosos e que os induzem a continuar participando do grupo, bem como estimulam outras pessoas para que frequentem. ${ }^{4,19}$

O envolvimento grupal é fator psicossocial significativo na melhoria da confiança pessoal, da satisfação com a vida e da capacidade de enfrentar problemas, pois por meio dos encontros, idosos resgatam a autoestima, sentem-se mais úteis e veem que a vida tem sentido, que a velhice não significa estar parado em casa esperando a morte chegar, e sim aproveitar a vida e viver cada minuto com intensidade. O vínculo criado é ingrediente fundamental na relação dos idosos que frequentam o mesmo grupo. ${ }^{20}$

Ao ingressarem no grupo, as mudanças foram significativas na vida dos idosos, que relataram mudança total, inclusive quanto à vontade de viver. A vida dos idosos, antes de entrar no grupo, era marcada por solidão, tristeza, monotonia, doenças, sofrimento por desvalorizações e preconceitos, pois ainda são vistos como pessoas improdutivas e quando se chega a essa fase da vida sofrem muito pelo desrespeito da sociedade.

O apoio social ajuda na prevenção, manutenção e recuperação da saúde. A autoestima e autopercepção são fundamentais ao autocuidado e a todas as medidas que a pessoa possa tomar para melhorar a saúde e o bem-estar no decorrer das atividades cotidianas. ${ }^{3}$ A importância em participar dos encontros está em proporcionar ganhos para a vida do idoso, pois o propósito do grupo vai ao encontro da promoção do envelhecimento ativo, preservação da capacidade e do potencial do indivíduo trabalhando no fortalecimento da autonomia, integração, saúde e socialização. ${ }^{21}$ Participar de atividades programadas para serem desenvolvidas em grupo faz com que o idoso pertença a um espaço no qual seus integrantes se caracterizam pela vontade de envelhecer ativamente, utilizando o tempo livre. ${ }^{16}$

As mudanças que acontecem no cotidiano dos idosos os fazem redimensionar perspectivas de futuro e reconhecimento enquanto cidadãos com direitos e deveres. Há o direito à liberdade, ao respeito e à dignidade, que são retirados do ser humano tão logo se alcança a terceira idade. As atividades desenvolvidas pelos grupos melhoram a qualidade de vida dos idosos nos aspectos referentes à saúde física e mental, aumentam o período de vida ativa e previne perdas funcionais. ${ }^{18}$

Este estudo apresentou como limitação a necessidade de repetição das perguntas do instrumento de coleta de dados, para os participantes, devido à dificuldade de compreender de imediato os questionamentos feitos, prolongando o tempo da entrevista, gerando estresse emocional nos entrevistados.

\section{CONSIDERAÇÃO FINAL}

Ao avaliar os grupos de convivência de idosos em Cajazeiras-PB, foi possível constatar predominância do sexo feminino, elevado número de viúvos, aposentados e com baixa escolaridade. Observou-se também que os idosos que participam dos grupos de convivência afirmaram receber incentivos dos familiares para participar dos grupos.

Para os idosos, a participação nos grupos significa uma forma de voltar para o convívio social, pois na maioria das vezes, quando envelhecem, enfrentam graves problemas. A inclusão nos grupos de convivência acontece por várias razões e motivos, como redução da solidão, a possibilidade de realidade das atividades de lazer, convivência com outros idosos, sensação de liberdade, vontade de viver e, consequentemente, melhoria da qualidade de vida.

Espera-se que este estudo desperte nas autoridades a proposta da criação de novos grupos de convivência, que reconheçam a pessoa idosa como uma das prioridades, com o propósito de ressocialização de idosos, para que a imagem de velhice sofrida, monótona e estereotipada seja substituída pela imagem de velhice sem sofrimento, com saúde e autonomia. 
Dessa forma, o grupo de convivência representa lugar de humanização e entendimento, uma vez que envelhecer faz parte do ciclo da vida e é preciso estar bem preparado física e psicologicamente. O ser humano não somente

\section{REFERÊNCIAS}

1. Andrade NA, Fernandes MGM, Nóbrega MML, Garcia TR, Costa KNFM. Análise do conceito fragilidade em idosos. Texto Contexto Enferm 2012;21(4):748-56.

2. Parahyba MI, Simões CCS. A prevalência de incapacidade funcional em idosos no Brasil. Ciênc Saúde Coletiva 2006;11(4):967-74.

3. Leite MT, Winck MT, Hildebrandt LM, Kirchner RM, Silva LAA. Qualidade de vida e nível cognitivo de pessoas idosas participantes de grupos de convivência. Rev Bras geriatr gerontol [Internet]. 2012 [acesso em 13 out 2012];15(3):481-92. Disponível em: http://www.scielo.br/scielo.php?pid=\$180998232012000300009\&script=sci_arttext

4. Beneditti TRB, Mazo GZ, Borges LJ. Condições de saúde e nível de atividade física em idosos participantes e não participantes de grupos de convivência de Florianópolis. Ciênc saúde coletiva [Internet]. 2012 [acesso em 13 out 2012];17(8):2087-93.

5. Lefèvre F, Lefèvre AMC. Princípios básicos e conceitos fundamentais do discurso do sujeito coletivo. In: Lefèvre F, Lefèvre AMC. O discurso do sujeito coletivo: um novo enfoque em pesquisa qualitativa; desdobramentos. Caxias do Sul: EDUCS; 2003. p. 15-35.

6. Andrade AN, Fernandes MGM, Nóbrega MML. Determinantes de fragilidade no idoso: uma revisão sistemática. Online Braz J Nurs [Internet]. 2010 [acesso em 10 fev 2012];9(1):1-13. Disponível em: EM: http://www.objnursing.uff.br/index.php/ nursing/article/view/j.1676-4285.2010.2847/649

7. Brasil. Conselho Nacional de Saúde. Resolução n. 196 de 10 de outubro de 1996. Dispõe sobre diretrizes e normas regulamentadoras de pesquisas envolvendo seres humanos. Bioética 1996;4(2 Suppl):15-25.

8. Leite MT, Hildebrandt LM, Kirchner RM, Winck MT, Silva LAA, Franco GP. Estado cognitivo e condições de saúde de idosos que participam de grupos de convivência. Rev Gaúcha Enferm 2012;33(4):64-71. necessita envelhecer de maneira saudável, como também com segurança, sentindo-se ativo e estando inserido no convívio social, pois esses fatores irão garantir uma velhice bem-sucedida.

9. Helder OS, Maynna JADC, Flávia ELL, Leila VR, Perfil epidemiológico de idosos frequentadores de grupos de convivência no município de Iguatu, Ceará. Rev Bras Geriatr Gerontol [Internet]. 2011[acesso em 13 out 2012];14(1):123-33. Disponível em: http://revista.unati. uerj.br/scielo.php?script=sci_arttext\&pid=\$180998232011000100013\&lng=pt\&nrm=iso

10. Ferreira PCS, Tavares DMS, Rodrigues RAP. Características sociodemográficas, capacidade funcional e morbidades entre idosos com e sem declínio cognitivo. Acta Paul Enferm 2011; 24(1):29-35.

11. Souza TR. Lazer, turismo e políticas públicas para a terceira idade. Rev Cient Eletr Turismo. 2006; 3(4):1-6.

12. Martins JJ, Schier J, Erdmann AL, Albuquerque GL. Políticas públicas de atenção à saúde do idoso: reflexão acerca da capacitação dos profissionais da saúde para o cuidado com o idoso. Rev Bras Geriatr Gerontol. 2007; 10(3):106-10.

13. Borges PLC, Bretas RP, Azevedo SF, Barbosa JMM. Perfil dos idosos freqüentadores de grupos de convivência em Belo Horizonte, Minas Gerais, Brasil. Cad Saúde Pública 2008;24(12):2798-808.

14. Costa FG, Campos PHF. Representação social da velhice, exclusão e práticas institucionais. Rev Eletr Psicol Políticas Públicas [Internet]. 2009 [acesso em 23 abr 2010];1(1):100-3. Disponível em: http://www. crp09.org.br

15. Leite MT, Moura C, Berlezi EM. Doenças sexualmente transmissíveis e HIV/AIDS na opinião de idosos que participam de grupos de terceira idade. Rev Bras Geriatr Gerontol. 2007; 10(3):339-54.

16. Leite MT, Cappellari VT, Sonego J. Mudou, mudou tudo na minha vida: experiências de idosos em grupos de convivência no município de IJUÍ/RS. Rev Eletr Enf [Internet]. 2002 [acesso em 13 mai 2010];4(1):1825. Disponível em: http://www.revistas.ufg.br/index. php/fen/article/view/746/81118

17. Veras R. FORUM. Envelhecimento populacional e as informações de saúde do PNAD: demandas e desafios contemporâneos. Cad Saúde Pública. 2007; 23(10):2463-66. 
18. Saulo VR, Maura MGA, Tania MA, Loiamara BS, Wisla KMR. Fatores associados à atividade física insuficiente no lazer entre idosos. Rev Bras Med Esporte. 2013;19(3): 191-5.

19. Salgado MA. Os grupos e a ação pedagógica do trabalho social com idosos. Rev Terc Idade [Internet]. 2007 [acesso 2010 out 13]; 18(39). Disponível em: www.sescsp.org.br/sesc/revistas/ti/index. cfm?forget $=13$ \& revista.
20. Assis M, Pacheco LC, Menezes IS. Repercussões de uma experiência de promoção de saúde no envelhecimento: análise preliminar a partir das percepções dos idosos. Textos Envelhecimento. 2002; 4(7):53-73.

21. Gárcia MAA, Yagi GH, Souza CS, Odoni APC, Frigério RM, Merlin SS. Atenção à saúde em grupos sob a perspectiva dos idosos. Rev Latino-am Enfermagem. 2006; 14(2):175-82. 